\title{
Optimization of the Main Landing Gear Structure of LSU-02NGLD
}

\author{
Fajar Ari Wandono ${ }^{1, a}$ \\ ${ }^{1}$ Aeronautics Technology Center, LAPAN, Jalan Raya LAPAN-Rumpin Desa Sukamulya, \\ Rumpin, Bogor 16350, Indonesia \\ aemail fajar.ari@lapan.go.id
}

\begin{abstract}
The mass of the landing gear structure becomes an important aspect of the total mass of the UAV (unmanned aerial vehicle). Therefore, many efforts have been made to reduce the mass of the landing gear by performing structural optimization. Reducing the mass of the landing gear structure can be used as a substitute to increase the payload on the UAV. The landing gear structure in this paper is the main landing gear of LSU-02NGLD (LAPAN Surveillance UAV series 02 New Generation Low Drag). LSU-02NGLD is a UAV that has $2.9 \mathrm{~m}$ of wingspan with a total mass of $21 \mathrm{~kg}$. This paper aims to optimize the main landing gear structure so that optimization can reduce the mass. The optimization was carried out using the finite element software by modeling the main landing gear structure as a 1D beam element. There were 9 beam elements in the main landing gear structure model. The cross-sectional width $(w)$ and the cross-sectional height $(h)$ for each element were used as design variables. The objective of the optimization was to minimize the mass while maintaining maximum bending stress not greater than $20 \mathrm{MPa}$, displacement in y-direction not greater than $1 \mathrm{~mm}$, and displacement in z-direction not greater than $0.1 \mathrm{~mm}$. The optimization result showed that the mass reduction of the main landing gear structure was $50 \%$, with all constraints fulfilled.
\end{abstract}

Keywords: Main Landing Gear Structure, Unmanned Aerial Vehicle, LSU-02NGLD, Optimization, Finite Element, Beam Element.

\section{Introduction}

The landing gear structure has a role in supporting the maneuvers of a UAV while on the ground, such as taxiing, take-off, and landing. The mass of the landing gear structure is important to the total mass of the UAV. Therefore, many efforts have been made to reduce the mass of the landing gear structure by optimizing the structure. Reducing the mass of the landing gear structure can be used as a substitute to increase the payload on the UAV [1].

The landing gear structure in this paper is the main landing gear structure of LSU-02NGLD (LAPAN Surveillance UAV series 02 New Generation Low Drag). LSU-02NGLD has a wingspan of $2.9 \mathrm{~m}$ with a total mass for the takeoff is about $21 \mathrm{~kg}$ [2]. LSU-02NGLD is shown in Figure 1. 


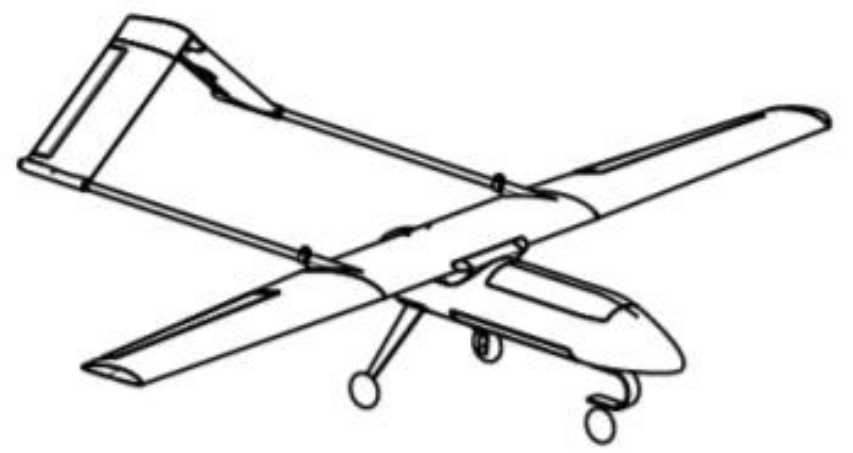

Figure 1. LSU-02NGLD [2]

Matta et al. performed design optimization on a main landing gear structure and axle of the UAV using a 2D element model. The landing gear and axle structure were divided into 11 areas whose thickness varied to obtain optimum mass. The result of this optimization was the mass could be reduced from $6 \mathrm{~kg}$ to $4.15 \mathrm{~kg}$ [1].

Teja \& Govindarajulu [3] optimized the design of a main landing gear structure by reducing the area of the main landing gear structure while still maintaining the design's safety. The optimization results were then analyzed using static analysis to determine the displacement, force, and stress in the structure.

\section{Theoretical Background}

In this paper, the main landing gear will be modeled on several beam elements. $A$ beam is a structure that has a small cross-sectional dimension relative to its length. A Beam is an important load-carrying component that internally experiences compressive, tensile, and shear stresses due to the loads given to the structure [4].

For modern structures, the mass reduction becomes very important besides performance. Therefore, the beam structure design must be well calculated to reduce the mass of the structure.

$$
\mathbf{k}=\left[\begin{array}{cccccc}
u_{i} & v_{i} & \theta_{i} & u_{j} & v_{j} & \theta_{j} \\
\frac{E A}{L} & 0 & 0 & -\frac{E A}{L} & 0 & 0 \\
0 & \frac{12 E I}{L^{3}} & \frac{6 E I}{L^{2}} & 0 & -\frac{12 E I}{L^{3}} & \frac{6 E I}{L^{2}} \\
0 & \frac{6 E I}{L^{2}} & \frac{4 E I}{L} & 0 & -\frac{6 E I}{L^{2}} & \frac{2 E I}{L} \\
-\frac{E A}{L} & 0 & 0 & \frac{E A}{L} & 0 & 0 \\
0 & -\frac{12 E I}{L^{3}} & -\frac{6 E I}{L^{2}} & 0 & \frac{12 E I}{L^{3}} & -\frac{6 E I}{L^{2}} \\
0 & \frac{6 E I}{L^{2}} & \frac{2 E I}{L} & 0 & -\frac{6 E I}{L^{2}} & \frac{4 E I}{L}
\end{array}\right]
$$

Figure 2. The stiffness matrix of the simple beam [5]

Where $k$ is the stiffness of the element, $E$ is the modulus of elasticity, $A$ is the cross-sectional area, $L$ is the length of the element, $l$ is the moment of inertia, $u$ is the axial displacement, $v$ is 
the lateral displacement, $\theta$ is the rotation. The bending stress can be calculated by Equation 1 below.

$\sigma=-M y / I$

Where $\sigma$ is the bending stress, $M$ is the bending moment, $y$ is the distance to the neutral axis, $I$ is the moment of inertia. Several important things to consider in optimization are design variables, objectives, and constraints. Design variables can change related to dimensions, grid location, and material properties either directly or indirectly [6].

The objective function is to minimize or maximize the considered responses. The objective functions of optimization are usually mass, strain energy, frequency, and compliance [6]. A constraint is one or more considered responses that are expected to be constrained in an optimization process. Constraints are usually in the form of stress, displacement, and mass fraction.

According to Larsson [7], design variables representing the thickness of the structure and or cross-sectional area that can minimize physical quantity such as mass, strain energy, or deflection by satisfying the constraints can be referred to as size optimization. Here is a general formula for structure optimization.

$$
\left\{\begin{array}{l}
\text { Minimize } f(x) \\
\text { Subjected to }\left\{\begin{array}{l}
g(x) \leq 0 \\
h(x)=0
\end{array}\right.
\end{array}\right.
$$

Where $f(x)$ is optimization's objective, $g(x)$ and $h(x)$ is optimization's constraint.

According to [8], the purpose of optimization is to get the best design against several priority criteria or constraints. Therefore, a design that includes an optimization process always considers certain objectives such as strength, deflection, mass, and others according to their needs.

\section{Materials and Methods}

The material used in this paper was assumed as Aluminum Alloy 7075-T6 material. This material was also used by Teja et al [3] and Yildirim et al [9] in their paper.

Table 1. Mechanical properties of Al 7075-T6 [3,9]

\begin{tabular}{ccccc}
\hline Al Alloy & Modulus of Elasticity (GPa) & $\begin{array}{c}\text { Yield Strength } \\
(\mathrm{MPa})\end{array}$ & $\begin{array}{c}\text { Poisson's } \\
\text { Ratio }\end{array}$ & $\begin{array}{c}\text { Density } \\
(\mathrm{kg} / \mathrm{m} 3)\end{array}$ \\
\hline $7075-\mathrm{T} 6$ & 72 & 505 & 0.33 & 2850 \\
\hline
\end{tabular}

The loads on the LSU-02NGLD used CASR Part 23 in Appendix C concerning Basic Landing Conditions as a reference. This reference was also used by Nguyen [10] and Wandono et al [11]. Here are the loads on the main landing gear structure when landing. 
Table 2. The loads on the main landing gear structure [11]

\begin{tabular}{lc}
\hline \multicolumn{1}{c}{ Load } & Value $(\mathrm{N})$ \\
\hline Vertical load $(\mathrm{Vr})$ & 245 \\
- each main landing gear structure & \\
Horizontal load (Dr) & 78.75 \\
- each main landing gear structure & \\
\hline
\end{tabular}

The following figure is a flow chart for performing optimization of the main landing gear of LSU02NGLD.

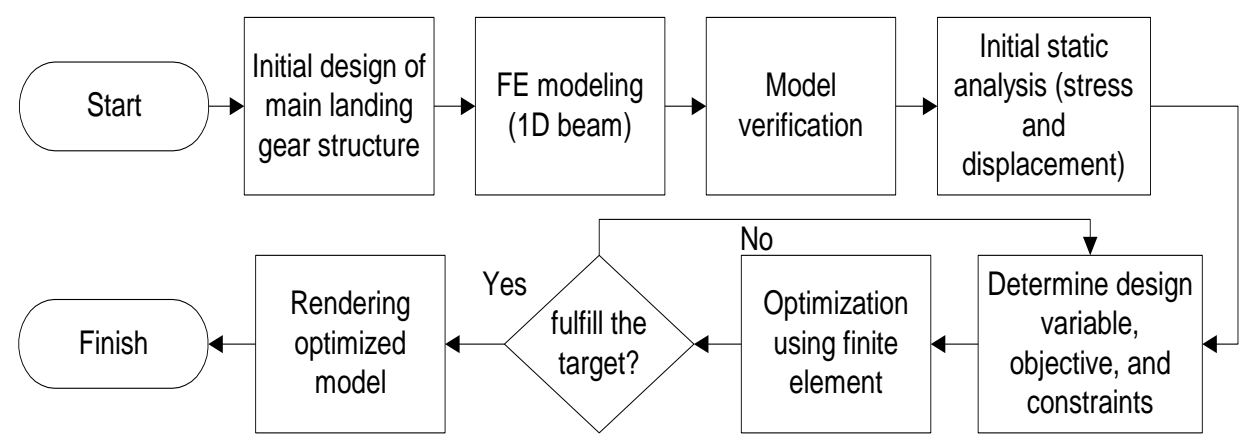

Figure 3. Flow chart

This paper started with the initial design of the main landing gear structure. In this initial design, the main landing gear structure had a uniform cross-section from the base to the tip, as shown in Figure 4.

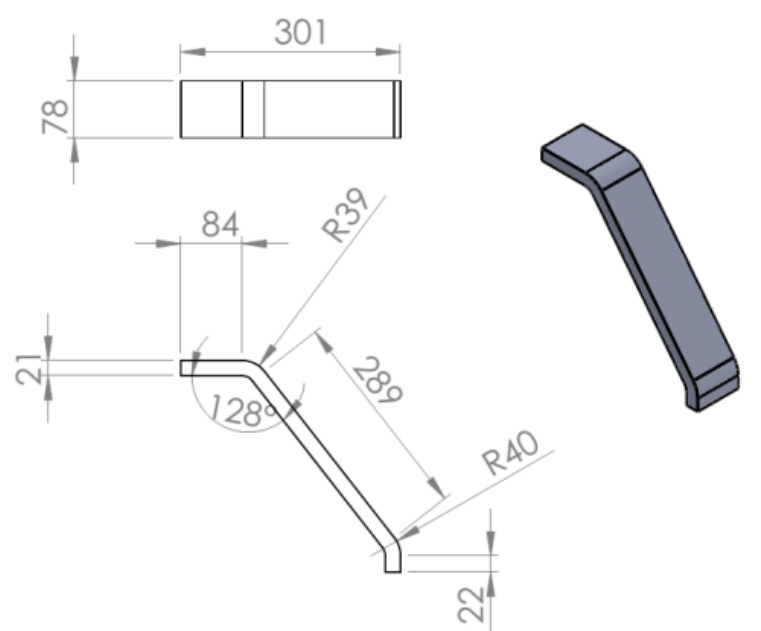

Figure 4. The initial design of the main landing gear structure $(\mathrm{mm})$

The initial design of the main landing gear was then modeled into a finite element using a 1D beam element. Here is a finite element model of the main landing gear. 


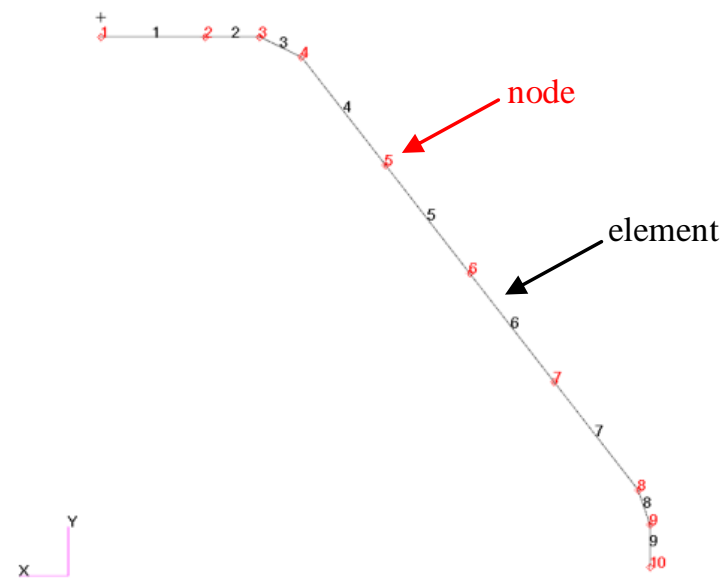

Figure 5. Finite element model of the main landing gear structure

Figure 5 shows that there are 9 elements (black) and 10 nodes (red) in the finite element model of the main landing gear structure. The cross-section used in the finite element model of the main landing gear is rectangular with a length of $78 \mathrm{~mm}$ and a height of $21 \mathrm{~mm}$, as shown in Figure 4.

The finite element model of the main landing gear was then verified to determine the finite element model is similar to the initial design of the main landing gear. Verification will show a 3D image of the finite element model after defining its cross-sectional.

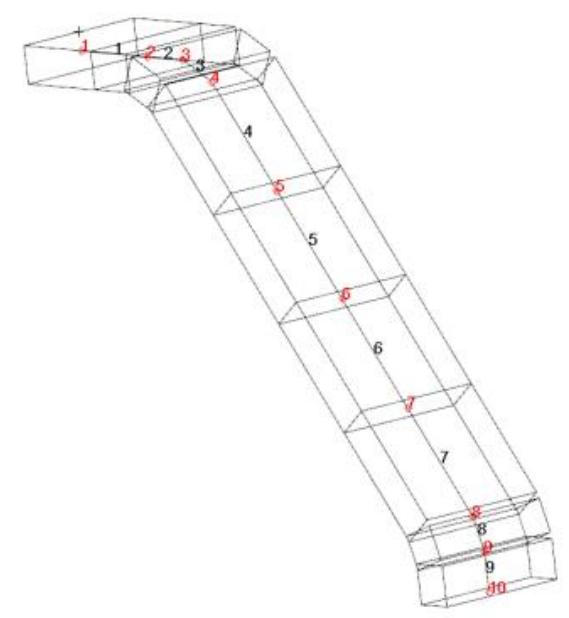

Figure 6. Model verification

Model verification in Figure 6 shows that the finite element model of the main landing gear is similar to the initial design, as shown in Figure 4. 


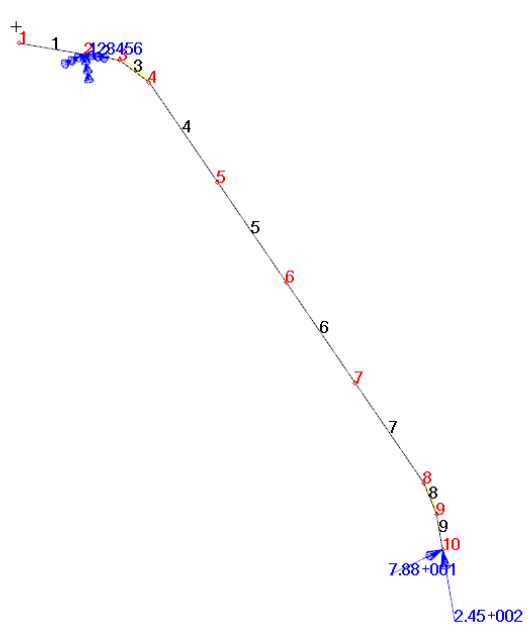

Figure 7. Load and boundary condition

Figure 7 shows the load and boundary conditions used in the finite element model of the main landing gear structure. The loads are subjected at the end of the main landing gear structure (node 10) with a value of $245 \mathrm{~N}$ in the y-direction and $78.75 \mathrm{~N}$ in the z-direction, as shown in Table 2. The boundary condition is fixed at node 2. The location of the boundary conditions follows the bolts' location for joining the main landing gear structure to the fuselage of LSU02NGLD.

Here are the results of the initial design static analysis of the main landing gear structure using the finite element software. The results are bending stress, displacement in the $y$-direction, and displacement in the z-direction.
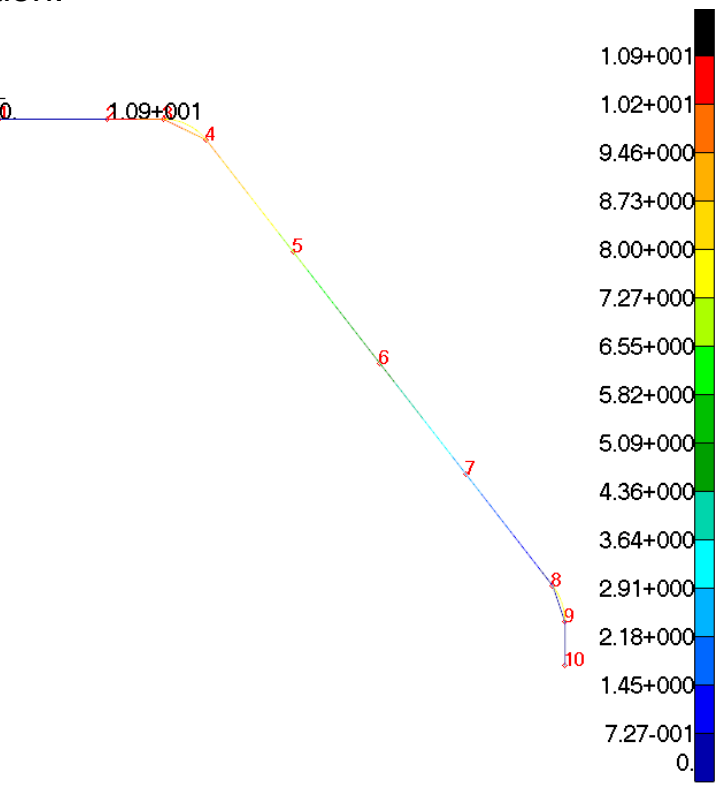

Figure 8. Bending stress distribution 
Figure 8 shows the distribution of bending stress on the main landing gear structure. The maximum bending stress occurs in element 2 , adjacent to the boundary condition, with a value of $10.9 \mathrm{MPa}$.

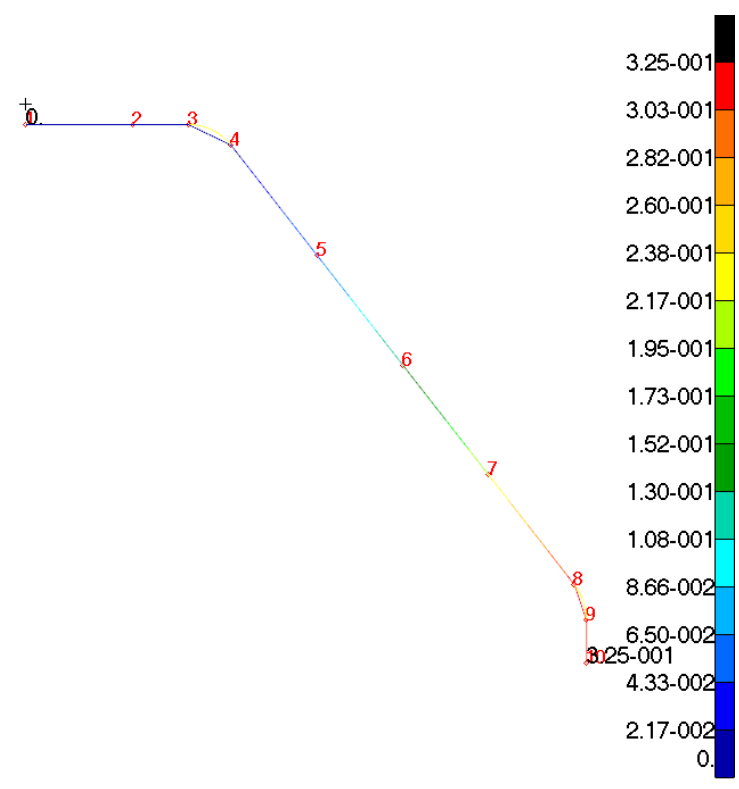

Figure 9. Displacement in y-direction

Figure 9 shows the displacement in the y-direction of the main landing gear structure model. The maximum displacement occurs at the end of the structure at node 10 with a value of 0.325 $\mathrm{mm}$.

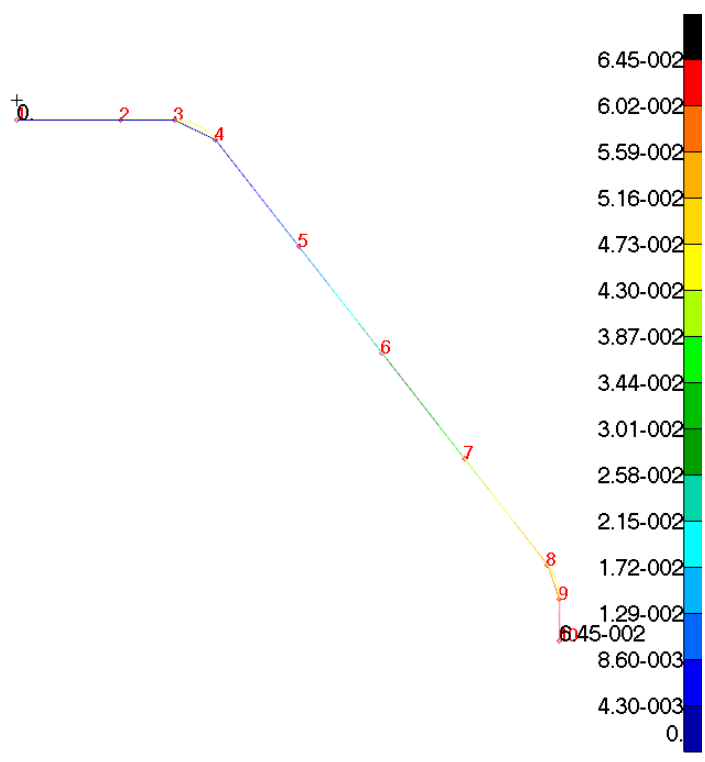

Figure 10. Displacement in z-direction

Figure 10 shows the displacement in the z-direction of the main landing gear structure model. The maximum displacement occurs at the end of the structure at node 10 with a value of 0.0645 $\mathrm{mm}$. For the maximum displacement, both y-direction and z-direction are at the loading location. 
The bending stress, displacement in the y-direction, and displacement in the z-direction will be used as references to determine the constraints for optimizing the main landing gear structure. The main landing gear structure model consisted of 9 beam elements. The design variables used were cross-sectional height $(h)$ and cross-sectional width $(w)$ for each element. Here is a table of design variables for the main landing gear structure optimization.

Table 3. Design variables

\begin{tabular}{ccccc}
\hline No & Design variable & Lower Bound & Upper Bound & Interval \\
\hline 1 & h1 & 10 & 21 & $10 \leq \mathrm{h} 1 \leq 21$ \\
2 & h2 & 10 & 21 & $10 \leq \mathrm{h} 2 \leq 21$ \\
3 & h3 & 10 & 21 & $10 \leq \mathrm{h} 3 \leq 21$ \\
4 & h4 & 10 & 21 & $10 \leq \mathrm{h} 4 \leq 21$ \\
5 & h5 & 10 & 21 & $10 \leq \mathrm{h} 5 \leq 21$ \\
6 & h6 & 10 & 21 & $10 \leq \mathrm{h} 6 \leq 21$ \\
7 & h7 & 10 & 21 & $10 \leq \mathrm{h} 7 \leq 21$ \\
8 & h8 & 10 & 21 & $10 \leq \mathrm{h} 8 \leq 21$ \\
9 & h9 & 10 & 21 & $10 \leq \mathrm{h} 9 \leq 21$ \\
10 & w1 & 50 & 78 & $50 \leq \mathrm{w} 1 \leq 78$ \\
11 & w2 & 50 & 78 & $50 \leq \mathrm{w} 2 \leq 78$ \\
12 & w3 & 50 & 78 & $50 \leq \mathrm{w} 3 \leq 78$ \\
13 & w4 & 50 & 78 & $50 \leq \mathrm{w} 4 \leq 78$ \\
14 & w5 & 50 & 78 & $50 \leq \mathrm{w} 5 \leq 78$ \\
15 & w6 & 50 & 78 & $50 \leq \mathrm{w} 6 \leq 78$ \\
16 & w7 & 50 & 78 & $50 \leq \mathrm{w} 7 \leq 78$ \\
17 & w8 & 50 & 78 & $50 \leq \mathrm{w} 8 \leq 78$ \\
18 & w9 & 50 & 78 & $50 \leq \mathrm{w} 9 \leq 78$ \\
\hline
\end{tabular}

For the main landing gear structure optimization, the objective was to minimize the mass. The constraints were bending stress, displacement in the y-direction, and displacement in the zdirection. Based on the static simulation for the initial design with a uniform cross-section, the maximum bending stress is $10.9 \mathrm{MPa}$, the maximum displacement in the y-direction is 0.325 $\mathrm{mm}$, and the maximum displacement in the $\mathrm{z}$-direction is $0.0645 \mathrm{~mm}$.

When mass optimization is carried out on a structure, the mass value will be inversely proportional to the stress and displacement. This is because a smaller mass than the initial mass will make the stress and displacement increase. Therefore, the upper limit of the stress and displacement optimization results must be considered to keep the structure safe.

From Table 3, it can be seen that there are 18 design variables for the main landing gear structure optimization with an upper limit of $21 \mathrm{~mm}$ and a lower limit of $10 \mathrm{~mm}$ for crosssectional height and an upper limit of $78 \mathrm{~mm}$, and a lower limit of $50 \mathrm{~mm}$ for cross-sectional width. For the main landing gear structure optimization, the constraints and their limits are presented in Table 4.

Table 4. Constraints and their limits

\begin{tabular}{cc}
\hline Constraints & Value \\
\hline Bending stress ( $\sigma$ ) & $10 \mathrm{MPa} \leq \sigma \leq 20 \mathrm{MPa}$ \\
Displacement in the y-direction (uy) & $\mathrm{uy} \leq 1 \mathrm{~mm}$ \\
Displacement in the z-direction (uz) & $\mathrm{uz} \leq 0.1 \mathrm{~mm}$ \\
\hline
\end{tabular}


The bending stress, displacement in the y-direction, and displacement in the z-direction, used as constraints, must be within these limits in the optimization results. If optimization results obtain the constraint value out of bounds, something is wrong in the optimization process and it has to be redefined again.

\section{Results and Discussion}

Here is the optimization cycle of the main landing gear structure. Fig. 11 shows the design variables cycle; they are cross-sectional height $(h)$ and cross-sectional width $(w)$.

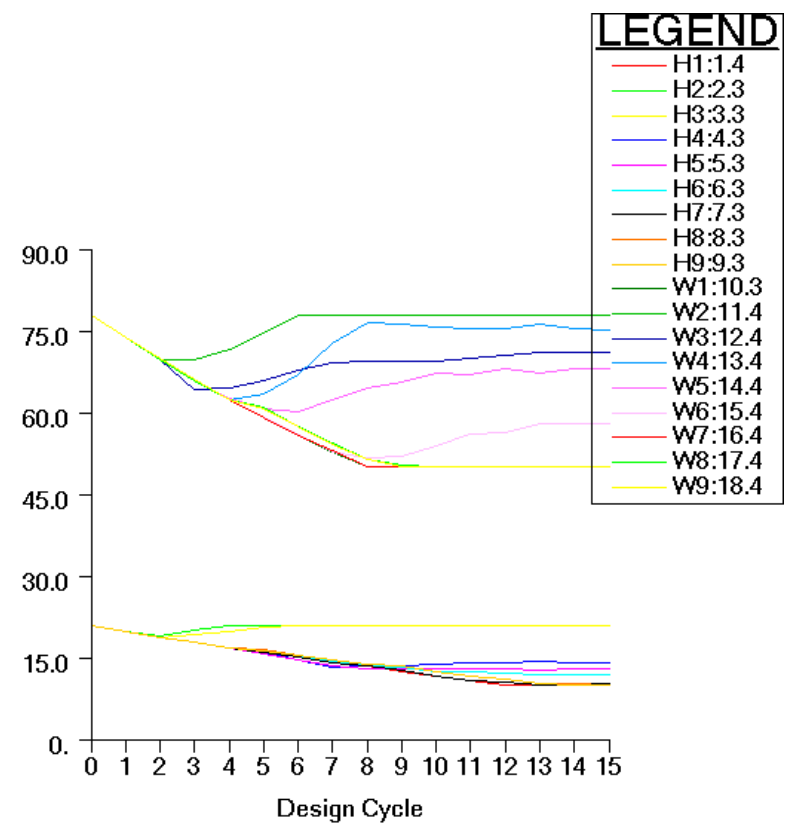

Figure 11. Design variable cycle graph

The bottom line set is the cross-sectional height $(h)$ cycle, and the top is the cross-sectional width $(w)$ cycle. The results of the design variable cycle stopped in the 15th iteration because the results had met the specified constraints. There was a design variable whose optimization value was similar to their initial value, and it occurred in element 2 , where the element was close to the boundary condition. The biggest changes occurred at the end (element $7,8,9$ ) and at the base (element 1) of the main landing gear structure, where the bending stress that occurred tends to be small. The objective cycle result is presented in Figure 12. 


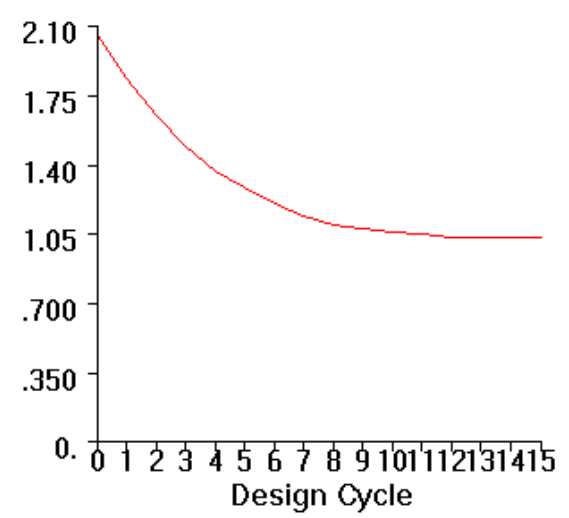

Figure 12. Objective cycle graph

From Figure 12 above, it can be seen that the initial mass of the main landing gear structure is about $2.05 \mathrm{~kg}$, and in the 15th iteration, the optimized mass is $1.025 \mathrm{~kg}$. Thus, the optimized main landing gear structure results in a mass reduction of about $50 \%$.

Table 5. Design variable comparison between initial and optimized design

\begin{tabular}{cccc}
\hline No & Design Variable & Initial & Optimized \\
\hline 1 & h1 & 21 & 10 \\
2 & h2 & 21 & 21 \\
3 & h3 & 21 & 21 \\
4 & h4 & 21 & 14.15 \\
5 & h5 & 21 & 12.96 \\
6 & h6 & 21 & 11.91 \\
7 & h7 & 21 & 10 \\
8 & h8 & 21 & 10 \\
9 & h9 & 21 & 10 \\
10 & w1 & 78 & 50 \\
11 & w2 & 78 & 78 \\
12 & w3 & 78 & 71.13 \\
13 & w4 & 78 & 75.17 \\
14 & w5 & 78 & 68.06 \\
15 & w6 & 78 & 58 \\
16 & w7 & 78 & 50 \\
17 & w8 & 78 & 50 \\
18 & w9 & 78 & 50 \\
\hline
\end{tabular}

The optimization results on the design variable were then displayed on the finite element model of the main landing gear structure. 


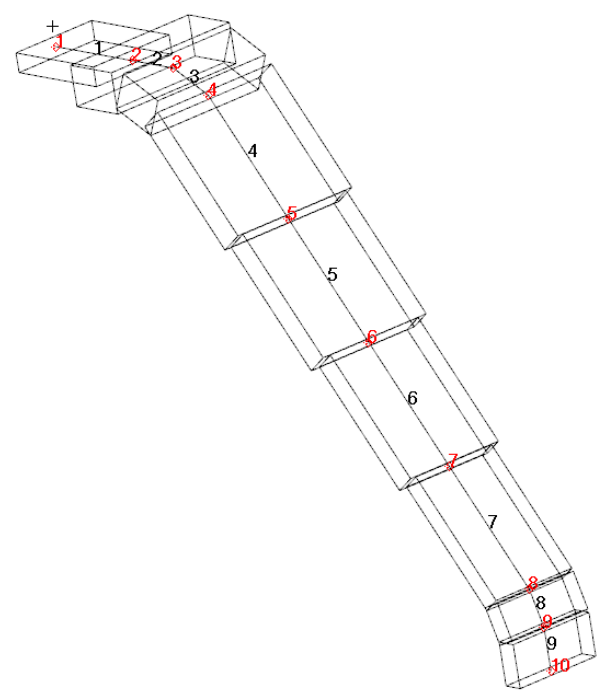

Figure 13. Optimized the main landing gear structure

From Figure 13, it can be seen that the results of the optimization of the main landing gear structure with bending stress and displacement in the y-direction and z-directions constraints get the results of a taper shape structure. Taper means the difference in height and width of the cross-section from the base to the tip of the main landing gear structure. For elements 1 and 9 , because they have small bending stress, the height and the cross-sectional width of the optimization results are also the smallest. Here are the results of bending stress, displacement in the $y$-direction, and displacement in the z-direction of the optimized design.

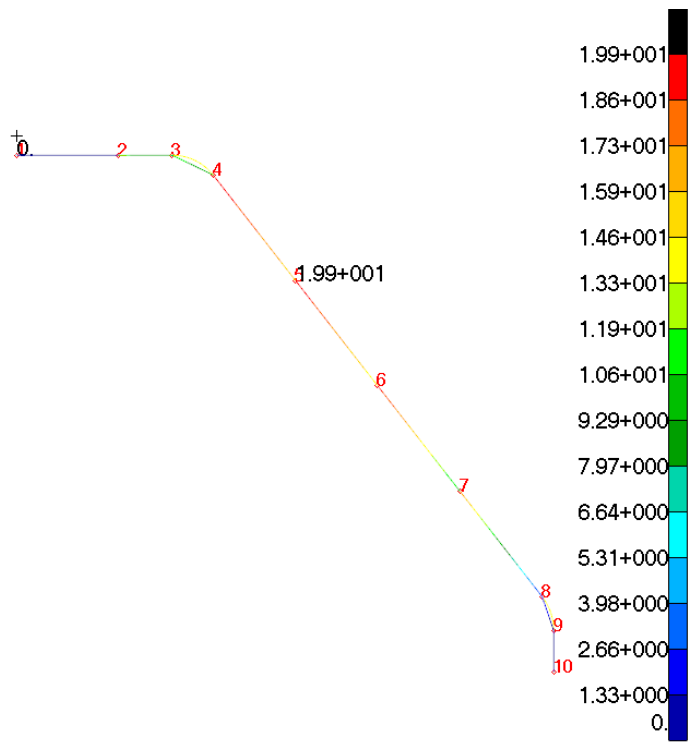

Figure 14. Bending stress distribution of the optimized design

Figure 14 is used to determine whether the results of the optimization of the structure fulfill the constraints. The figure above shows that the maximum bending stress on the optimized main landing gear structure is $19.9 \mathrm{MPa}$ at element 5. This fulfills one of the constraints that the 
maximum bending stress is $20 \mathrm{MPa}$. However, the maximum bending stress position in the optimization is different from the initial results. This is because the cross-sectional section of element 5 has been changed to be smaller, which makes the moment of inertia smaller and makes the bending stress larger.

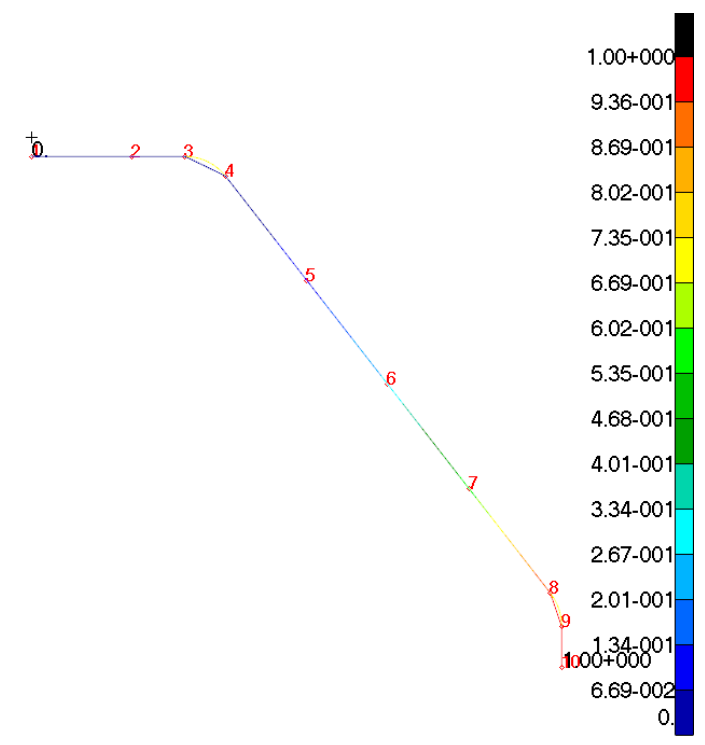

Figure 15. Displacement in the y-direction of the optimized design

Figure 15 above is also used to determine whether the results of the optimization of the structure fulfill the constraints. The figure above shows that the maximum displacement in $y$ direction on the optimized main landing gear structure is $1 \mathrm{~mm}$ at node 10 . This also fulfills one of the constraints that the maximum displacement in the $y$-direction is $1 \mathrm{~mm}$.

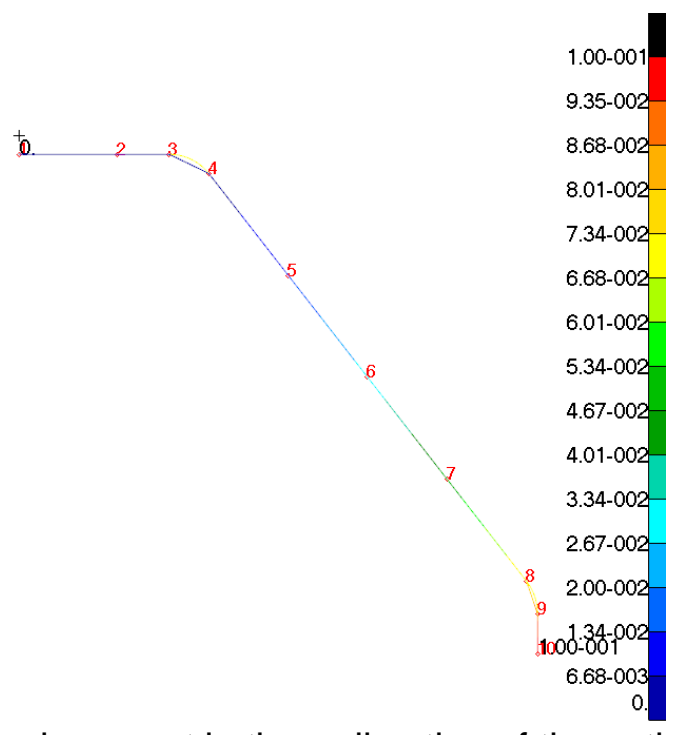

Figure 16. Displacement in the z-direction of the optimized design 
From Figure 16, it is known that the maximum displacement in the z-direction on the optimized main landing gear structure is $0.1 \mathrm{~mm}$ at node 10. Therefore, this also fulfills one of the constraints of the maximum displacement z-direction is $0.1 \mathrm{~mm}$.

Table 6. Comparison between initial and optimized design

\begin{tabular}{lllll}
\hline Configuration & $\sigma \max (\mathrm{MPa})$ & uy $\max (\mathrm{mm})$ & $u z \max (\mathrm{mm})$ & Mass $(\mathrm{kg})$ \\
\hline Initial & 10.9 & 0.325 & 0.0645 & 2.05 \\
Optimized & 19.7 & 1 & 0.1 & 1.025 \\
\hline
\end{tabular}

The next step was to redraw the optimization results because all requirements such as design variables and constraint constraints had been fulfilled. Here is the result of the optimized main landing gear structure.

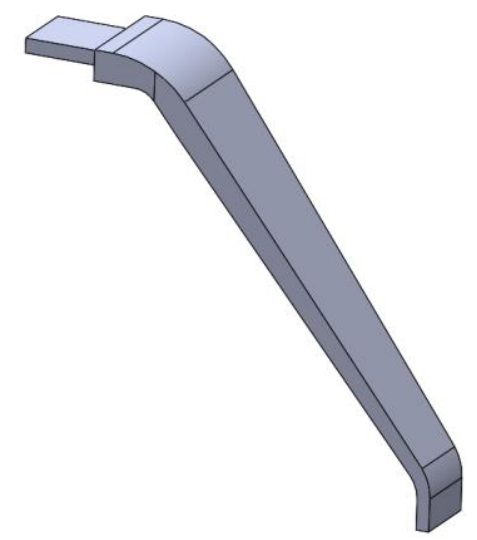

Figure 17. The optimized main landing gear structure

\section{Conclusions}

The optimization process has been carried out on the main landing gear structure of the LSU02NGLD. The optimization process was carried out on the finite element software by modeling the main landing gear structure as a 1D beam element. There were 9 beam elements in the main landing gear structure. The design variables used were cross-sectional height $(h)$ and cross-sectional width $(w)$ for each element. The objective of this optimization was to minimize the mass with a maximum bending stress constraint not greater than $20 \mathrm{MPa}$, displacement in $y$-direction not greater than $1 \mathrm{~mm}$, and displacement in z-direction not greater than $0.1 \mathrm{~mm}$. The optimization result showed that the mass reduction of the main landing gear structure is $50 \%$, with all constraints fulfilled.

\section{ACKNOWLEDGEMENTS}

The author would like to express many thanks to Mr. Drs. Gunawan S. Prabowo, MT as Head of the Aeronautics Technology Center and to Mr. Ir. Agus Aribowo, M.Eng for the support. 


\section{References}

[1] A.K. Matta, G.V. Kumar, and R.V. Kumar, 2012, Design Optimisation of Landing Gear's Leg For An Un-Manned Aerial Vehicle, International Journal of Engineering Research and Applications, volume 2, page $2069-2075$.

[2] F.A. Wandono and M. Adhitya, 2020, Finite Element Analysis for Composite Wing Structure of the Maritime Surveillance Unmanned Aerial Vehicle, Padang.

[3] C. A. Teja and C. Govindarajulu, 2019, Optimization of Conventional Type Landing Gear's Leg, Journal of Engineering Research and Application, volume 9, no. 11, page $52-56$.

[4] S. Darshan, A. Varik, A. N. Katti, A. K. Singh and R. R. Kamath, 2013, Size and Topological Optimization of Cantilever Beam, Journal of Engineering Trends and Technology, volume 4, no. 5 , page $2077-2082$.

[5] Y. Liu, 2003, Lecture Notes: Introduction to the Finite Element Method, Cincinnati: University of Cincinnati.

[6] J. P. Leiva, 2004, Topometry Optimization: A New Capability to Perform Element by Element Sizing Optimization of Structures, 10th AIAA/ISSMO Multidisciplinary Analysis and Optimization Conference, New York.

[7] R. Larsson, 2016, Methodology for Topology and Shape: Optimization: Application to a Rear Lower Control Arm (Master's Thesis), Chalmers University of Technology, Goteborg.

[8] A. D. Kewate, R. R. Ghadge and S. R. Kewate, 2017, Weight Optimization of Composite Cantilever Structure, Journal of Material Science and Mechanical Engineering, volume 4, no. 4, page $172-178$.

[9] O. Yildirim, E. Gunay, O. Anil and C. Aygun, 2014, Analysis of a Skid Type Landing Gear of a Rotary Wing UAV by Experimental and Numerical Methods, Proceedings of the 4th International Congress APMAS, Fethiye.

[10] T. D. Nguyen, 2010, Finite Element Analysis of a Nose Gear During Landing. UNF Theses and Dissertations, University of North Florida, Florida.

[11] F. A. Wandono and M. Adhitya, 2019, Analisis Kekuatan Struktur Komposit Dengan Ply Drop Off Pada Roda Pendarat Utama Pesawat Nir Awak Menggunakan Metode Elemen Hingga, Jurnal Teknologi Dirgantara, volume 17, page 29 - 40. 